\title{
Article \\ The Impact of Lubricant Film Thickness and Ball Bearings Failures
}

\author{
Matthew Marko ${ }^{1 *}$ \\ Naval Air Warfare Center Aircraft Division Joint-Base McGuire-Dix-Lakehurst, Lakehurst NJ 08733, USA ${ }^{1}$ \\ * Correspondence: matthew.marko@navy.mil
}

\begin{abstract}
An effort was made to find a relationship between the predicted tribological conditions at the point of contact of ball bearings, and empirical equations to predict the life for bearings under constant motion. The model was modified to predict the temperature dependence, and compare rapid accelerations and decelerations with empirical extrapolations.
\end{abstract}

Keywords: Lubrication, Ball Bearings, Roller Bearings, Failures, L10, Film Thickness

\section{Introduction}

Ball bearings are used in countless mechanical applications to convert sliding mechanical contact into rolling contact [1-3], dramatically reducing friction energy losses. Sliding contact inherently has a high friction force, as random asperities can contact the surface and induce wear and damage to machined parts [4-7]. Rolling contact, however, has dramatically lower friction; the overwhelming majority of the friction loss is merely hysteresis from elastic deflections of the circular bearings.

Rolling element bearings are one of the most common configuration of ball bearings, with the bearings contained in a circular race to allow continued circular motion. So long as there is a minimum surface friction to enable the bearings to roll, there will be a dramatic reduction in circular friction for an object spinning inside or outside of the races. Bearings can be spherical, cylindrical, or a host of different configurations depending on the applications of the ball bearings.

A well built bearing can last indefinitely, however all mechanical objects have some risk of failure. Despite the previous assumptions that stresses less than half of yield have no significant risk of failure, there is always some risk of fatigue and fracture, which may manifest itself in the life of a ball bearing. The most likely bearing failure, however, is lubricant failure causing the bearings to seize. Ball bearings overwhelmingly use lubricant oils and greases to ensure there isn't an excessive build-up of heat and friction between the races and the bearings. While a minimum amount of friction is necessary to ensure the bearings roll rather than slide (often specified as a minimum axial load), too much friction can cause the bearings to stick to the race and seize up, rather than allowing rolling.

Friction is inherently random and variable, as it is impacted by the different random surface asperities; as such it is incredibly difficult to model. The usual (but not exclusive) mechanism of lubricant failure is as followed: a high enough friction will heat the lubricant, which will reduce the viscosity of the lubricant, which will increase the friction heating, and this feedback loop will continue until the friction between the bearing and the races is so great that the bearing seizes. If a bearing seizes during a critical application, the results can be catastrophic.

While it is impossible to truly know the exact nature of every bearing surface, empirical equations can be generated to determine the $\mathrm{L}_{10}$ life from a known bearing load, lubricant cleanliness, lubricant viscosity, and continuous bearing speed. The $\mathrm{L}_{10}$ life is defined as the number of revolutions a bearing can experience before a $10 \%$ chance of bearing failure. This effort is to study how tribological properties such as the lubricant film thickness can serve to predict the change of failure after a single revolution, and thus estimate the $\mathrm{L}_{10}$ life.

1 NAVAIR Public Release 2018-609 Distribution Statement A - "Approved for public release; distribution is unlimited" 


\section{Empirical Equations for $L_{10}$ Life}

In order to properly develop a numerical model for ball bearing failures, it is necessary to have empirical data on bearing failure to verify and validate it. In this aim, the $\mathrm{L}_{10}$ empirical equations provided by Svenska Kullagerfabriken (SKF) will be used as a baseline; SKF is a Swedish company founded in 1907 and is currently the world's largest manufacturer of ball bearings. They have a bearing calculator that provides the $\mathrm{L}_{10}$ life in revolutions before the bearings have a $10 \%$ chance of failure. The core equation for $\mathrm{L}_{10}$ life is

$$
L_{10}=A_{S K F} \cdot\left(\frac{C}{P}\right)^{10 / 3} \cdot 10^{6},
$$

where $C(\mathrm{~N})$ is the basic dynamic load rating, $P(\mathrm{~N})$ is the equivalent load, and $A_{S K F}$ is the Life Modification Factor. The value of $A_{S K F}$ is a function of the the combined influence of load and contamination on fatigue $\beta$; and the viscosity ratio $\kappa$, which represents the lubrication conditions and their influence on fatigue.

The dimensionless value of $\kappa$ is a ratio of the kinematic viscosity $v\left(\mathrm{~m}^{2} / \mathrm{s}\right)$ over the rated viscosity $v_{1}\left(\mathrm{~m}^{2} / \mathrm{s}\right)$

$$
\kappa=\frac{v}{v_{1}},
$$

where $v_{1}$ is a function of both the speed $\Omega_{r p m}$ and the average bearing diameter $d_{m}(\mathrm{~m})$

$$
\begin{aligned}
v_{1} & =f\left(\Omega_{r p m}, d_{m}\right), \\
d_{m} & =\frac{1}{2} \cdot(D+d),
\end{aligned}
$$

where $D(\mathrm{~m})$ and $d(\mathrm{~m})$ represent the diameter of the inner and outer bearing race. The value of $\kappa$ can range from 0.1 to 4.0 , where $\kappa=0.1$ represents total metal-on-metal contact, and $\kappa=4.0$ represents a total lubricant coating. SKF did not publish their equation for $v_{1}$, but it can be determined from the SKF bearing calculator. A least squared analysis was performed, and an estimated function for the rated viscosity $v_{1}\left(\mathrm{~m}^{2} / \mathrm{s}\right)$ is defined in equation 3

$$
\nu_{1}=689.2653 \cdot 10^{-6} \cdot d_{m}{ }^{-0.52706} \cdot \Omega_{r p m}^{-0.7565},
$$

where the mean diameter $d_{m}$ is in meters and the bearing speed $\Omega_{r p m}$ is in revolutions per minute. Calculated values of $v_{1}\left(\mathrm{~m}^{2} / \mathrm{s}\right)$ are plotted in units of centistokes or $\mathrm{mm}^{2} / \mathrm{s}$ in Figure 1 .

The other term necessary to determine $A_{S K F}$ is the dimensionless coefficient $\beta$, which is the product of the cleanliness factor $N_{c}$ and the safety factor ratio of the fatigue load limit $P_{u}(\mathrm{~N})$ over the equivalent bearing load $P(\mathrm{~N})$

$$
\beta=N_{c} \cdot \frac{P_{u}}{P}
$$

The cleanliness factor $N_{c}$ ranges from 0.2 to 1.0, with 0.2 representing the dirtiest possible lubricant, and 1.0 representing a perfectly clean lubricant. The equivalent load $P(\mathrm{~N})$ is a combination of radial and axial loads [8]

$$
P=X_{a} \cdot F_{a}+X_{r} \cdot F_{r}
$$

where $F_{a}(\mathrm{~N})$ and $F_{r}(\mathrm{~N})$ are the axial and radial loads, and $X_{a}$ and $X_{r}$ are bearing specific coefficients. For example, for spherical thrust bearings $X_{a}=1$ and $X_{r}=1.2$. 


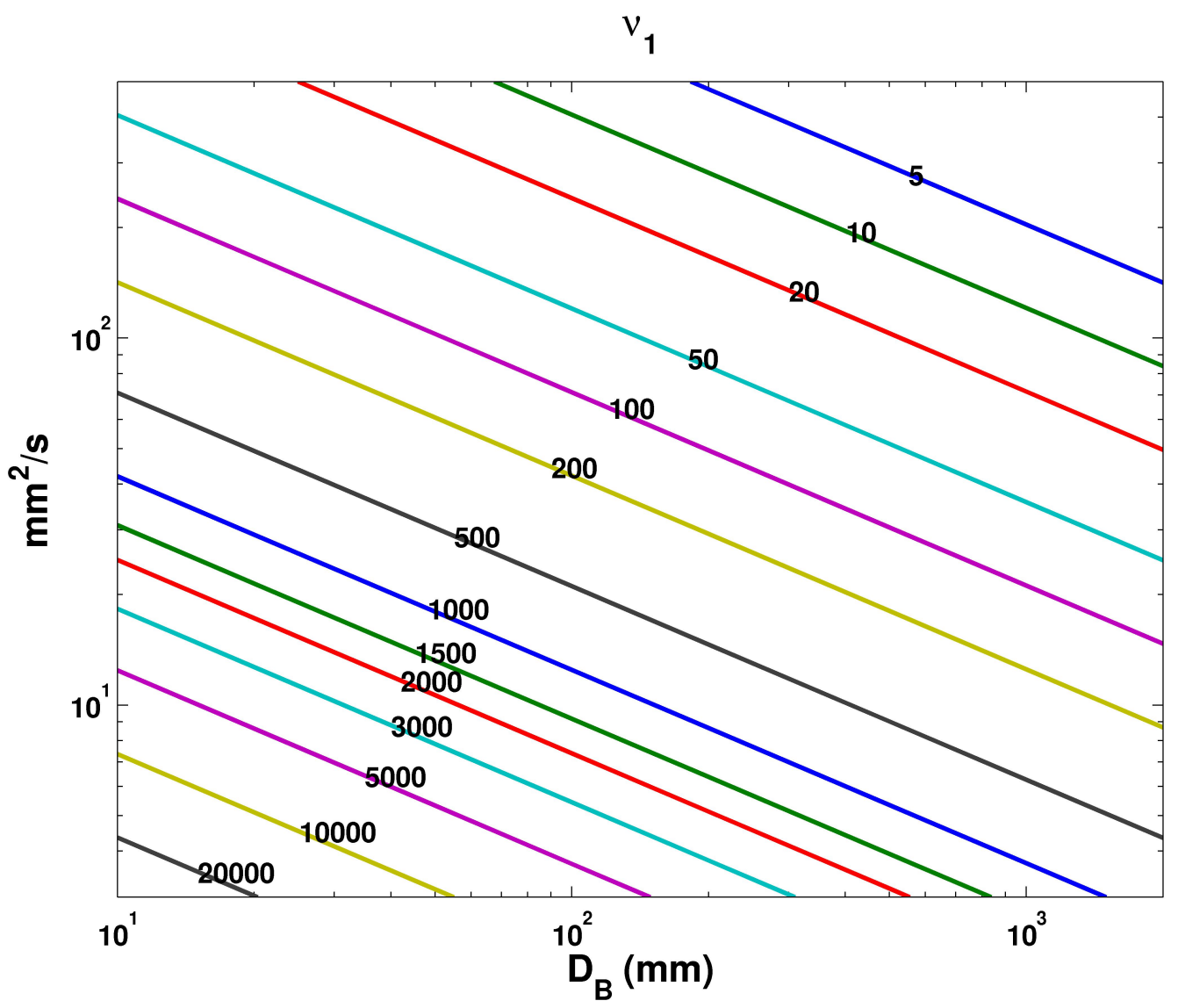

Figure 1. Values of $v_{1}\left(\mathrm{~mm}^{2} / \mathrm{s}\right)$ calculated with equation 3 as a function of average bearing diameter $d_{m}(\mathrm{~mm})$ and $\Omega_{r p m}$. 


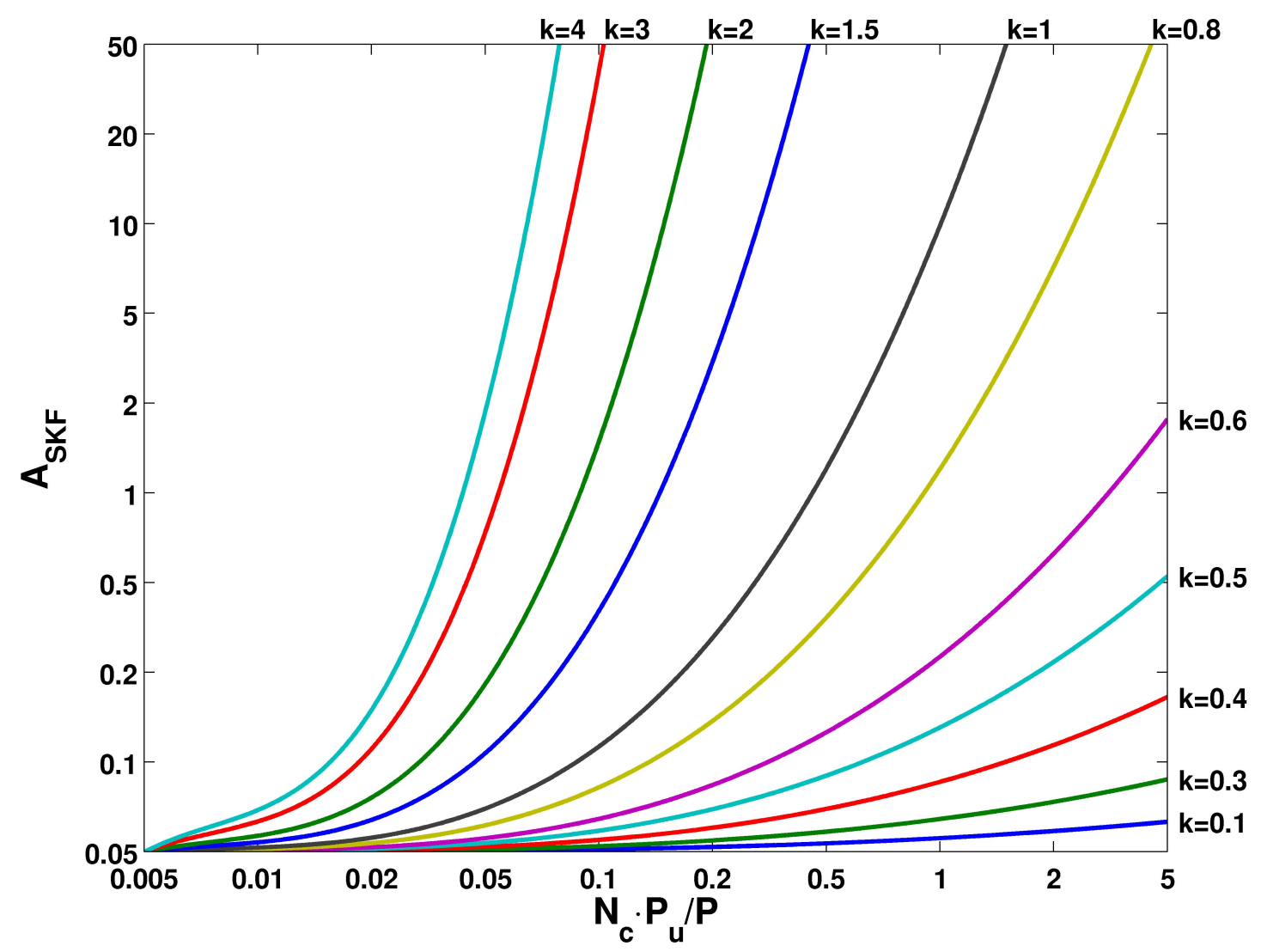

Figure 2. Values of $A_{S K F}$ calculated with equation 6 as a function of $\beta$ and $\kappa$.

The SKF website provides tables for the value of $A_{S K F}$ as a function of $\beta$ and $\kappa$, as well as a calculator tool, but no specific formula was given. For this reason, the least squared method was used, and a close match all throughout the permissible range of $\beta$ and $\kappa$ yielded the empirical equation 6

$$
A_{S K F}=\frac{1}{48.5658} \cdot \frac{C_{1,1} \cdot \kappa^{3}+C_{2,1} \cdot \kappa^{2}+C_{3,1} \cdot \kappa+C_{4,1}}{C_{1,2} \cdot \beta^{3}+C_{2,2} \cdot \beta^{2}+C_{3,2} \cdot \beta+C_{4,2}}
$$

where the values of $C_{i, j}$ is tabulated in Table 1 . Values of $A_{S K F}$ calculated with equation 6 as a function of $\beta$ and $\kappa$ are plotted in Figure 2. Once the value of $A_{S K F}$ is determined, it can be used in equation 1 to find the $\mathrm{L}_{10}$ life, defined as the number of revolutions the bearing can undergo before encountering a $10 \%$ chance of failure. If one were to determine the probability of failure during a single revolution of the bearings $P_{f}$, it can easily be defined as

$$
P_{f}=1-0.9^{1 / L_{10}}
$$

Table 1. Values of $C_{i, j}$ for equation 6 .

\begin{tabular}{|c||c|c|c|c|}
\hline & $i=1$ & $i=2$ & $i=3$ & $i=4$ \\
\hline$j=1$ & -1.0546438966 & 7.8035534479 & -2.2611216389 & 0.2506572545 \\
$j=2$ & 8.4323308847 & -8.2419247195 & 6.6722837673 & -0.043545982 \\
\hline
\end{tabular}




\section{Tribological Predictions of $L_{10}$ Life}

Equation 1 can predict the $\mathrm{L}_{10}$, but it gives no information as to the mechanics of the failure; it is a purely based on empirical data. In order to better understand the mechanism of failure, a model based on the tribological properties to find the values of $\mathrm{L}_{10}$ needs to be developed, with equation 1 being used to verify and validate this model.

Regardless of the $\mathrm{L}_{10}$ life, a ball bearing failure can happen; $\mathrm{L}_{10}$ life is really a function of the probability of failure in the face of random conditions such as surface asperities. The most common form of bearing failure is seizure, where excessive friction can yield increased heating, which reduces the lubricant viscosity, increasing the friction, until eventually the friction increases till it is high enough that the bearing seizes. Another potential cause of failure is a failure in fatigue; this will increase exponentially with increasing load relative to fatigue life. For the purpose of the analysis, the driving cause of failure will be treated as an excessively high increase in friction from the approximated average friction.

Friction is never constant in practice, it constantly fluctuates about a given average, therefore, this failure prediction model will be normalized to a given quantity of standard deviations away from the mean friction

$$
\begin{aligned}
P_{f} & =\frac{1}{2} \cdot \operatorname{erfc}(\mu), \\
\operatorname{erfc}(\mu) & =1-\frac{2}{\sqrt{\pi}} \cdot \int_{0}^{\mu} e^{-t^{2}} d t,
\end{aligned}
$$

where $\operatorname{erfc}$ represents the complementary error function, $\mu$ represents a high standard deviation away from the mean of a normal distribution to cause the probability of failure $P_{f}$ for a single revolution is defined in equation 7 , and thus the standard deviation of failure $\mu$ can be calculated as

$$
\mu=\operatorname{erfc}^{-1}\left\{2 \cdot\left(1-0.9^{1 / L_{10}}\right)\right\} .
$$

While $\mu$ is a parameter for the probability of failure, it also is a representation of the mean coefficient of friction. According to Greenwood and Williamson's research [9-14], wear and friction (other than from fluid stresses) occur due to random asperities exceeding the thickness of the lubricant film [9-16]. Assuming the surface asperities height follows a normal distribution, the ratio of metal-on-metal contact $A_{\text {real }} / A$ with the lubricant thickness should roughly follow

$$
\frac{A_{\text {real }}}{A} \approx \exp \left(-\frac{h}{\sigma}\right)
$$

where $A_{\text {real }}\left(\mathrm{m}^{2}\right)$ represents the true metal-on-metal contact area, $A\left(\mathrm{~m}^{2}\right)$ represents the apparent (but not true) surface contact area, $h(\mathrm{~m})$ represents the lubricant film thickness, and $\sigma(\mathrm{m})$ represents the RMS average asperities height. It is expected that the probability of lubricant failure will be a direct exponential function of the lubricant film thickness $h(\mathrm{~m})$ as described in equation 10.

\section{First Parametric Study}

A parametric study was conducted, utilizing the SKF NUP 2304-ECP cylindrical roller bearing. The radii of the individual cylindrical bearings are $R=4.455 \mathrm{~mm}$, and the length is $13.267 \mathrm{~mm}$; the mean radius that the bearings rotate at is $72 \mathrm{~mm}$. The fatigue load limit $P_{u}$ is $4,800 \mathrm{~N}$, and the basic dynamic load rating $C$ is $47,500 \mathrm{~N}$. The bearing is made of steel, so the Young's Modulus $E_{y}$ will be $210 \mathrm{GPa}$, and the poisson's ratio $p$ will be 0.3 . The parametric study would calculate both the $\mathrm{L}_{10}$ life as defined in equation 1 , and compare it to the predicted lubricant film thickness [8,17-28], as well as the relative fatigue load. The parametric study was conducted for a temperature ranging between $40^{\circ} \mathrm{C}$ and $100^{\circ} \mathrm{C}$, in increments of $2^{\circ} \mathrm{C}$; an equivalent load ratio of $50 \mathrm{kN}$ to $200 \mathrm{kN}$ (in increments of 10 $\mathrm{kN}$ ); and a bearing speed from 5,000 to 20,000 RPM, in increments of 1,000 RPM. With each of these 
parameters, the $\mathrm{L}_{10}$ life was calculated with equation 1 and equation 6 , and an equivalent $\mu$ was found with equation 9.

The next step was to predict the film thickness of the lubricant at the point of contact between the bearings and the rollers during elastohydrodynamic contact [1,29]. In 1974, empirical equations by Hamrock \& Dowson [22] characterized the minimum $h_{0}(\mathrm{~m})$ and central $h_{c}(\mathrm{~m})$ film thickness

$$
\begin{array}{r}
h_{\min }=3.63 R^{\prime}\left(U_{n}^{0.68}\right)\left(G_{n}^{0.49}\right)\left(W_{n}^{-0.073}\right)\left(1-\exp \left[-0.68 \kappa_{\text {ellipse }}\right]\right), \\
h_{c}=2.69 R^{\prime}\left(U_{n}^{0.67}\right)\left(G_{n}^{0.53}\right)\left(W_{n}^{-0.067}\right)\left(1-0.61 \cdot \exp \left[-0.73 \kappa_{\text {ellipse }}\right]\right), \\
U_{n}=\frac{\mu_{0} U}{E^{\prime} R^{\prime}}, \\
G_{n}=\alpha_{P V C} E^{\prime}, \\
W_{n}=\frac{W}{E^{\prime} R^{\prime 2}},
\end{array}
$$

where $h_{\min }(\mathrm{m})$ is the minimum film thickness, $h_{c}(\mathrm{~m})$ is the central film thickness, $U_{n}$ is the dimensionless speed parameter, $G_{n}$ is the dimensionless material parameter, $W_{n}$ is the dimensionless load parameter, $\kappa_{\text {ellipse }}$ is the ellipticity of the contact area, $\mu_{0}$ (Pa-s) is the dynamic viscosity of the lubricant at atmospheric pressure, $\alpha_{P V C}\left(\mathrm{~Pa}^{-1}\right)$ is the pressure viscosity coefficient, and $U(\mathrm{~m} / \mathrm{s})$ is the velocity of contact. The reduced Young's Modulus $E^{\prime}(\mathrm{Pa})$ and reduced radius $R^{\prime}(\mathrm{m})$ are for Hertz contact equations for elastic deflection [1,30]. Assuming spherical rollers and a consistent material is used, the equations for $E^{\prime}$ and $R^{\prime}$

$$
\begin{aligned}
& R^{\prime}=\frac{R}{2} \\
& E^{\prime}=\frac{E_{y}}{1-p^{2}} .
\end{aligned}
$$

where $R(\mathrm{~m})$ is the radius of the spherical bearing, and $E_{y}(\mathrm{~Pa})$ and $p$ is the Young's Modulus and Poisson's ratio of the bearing material.

If there is a given friction force that will cause the bearings to seize, and the friction is affected by the ratio of the height of the surface asperities (which follow a normal distribution) over the lubricant film thickness, an accurate equation for $\mu$ as a function of $h_{c}(\mathrm{~m})$ was realized with equation 18

$$
\mu=X_{1}+X_{2} \cdot \exp \left(-\frac{h_{c}}{\sigma}\right)+X_{3} \cdot \sqrt{\frac{P}{P_{u}}},
$$

where $\sigma$ was predicted as $100 \mathrm{~nm}$ RMS for the surface asperities, and $P_{u}$ was defined as $4,800 \mathrm{~N}$. The calculated value of $\mu$ found with equation 18 closely matches the value of $\mu$ found with equation 9 (utilizing empirical equations 1 and 6), with a coefficient of determination $R^{2}=0.9921$, and observed to match in Figure 3. The coefficients for this particular design is $X_{1}=5.1710, X_{2}=-0.8028$, and $X_{3}=0.2586$.

\section{Second Parametric Study}

A second parametric was conducted to see if varying the bearing size would affect the coefficients for equation 18. The mean bearing radius was modeled from $30 \mathrm{~mm}$ to $500 \mathrm{~mm}$, and the RMS surface asperities $\sigma(\mathrm{m})$ was linearly scaled with bearing radius

$$
\sigma=10^{-7} \cdot \frac{d_{m}}{0.072}
$$


7 of 11

\section{SKF 2310-E2RS1TN9}

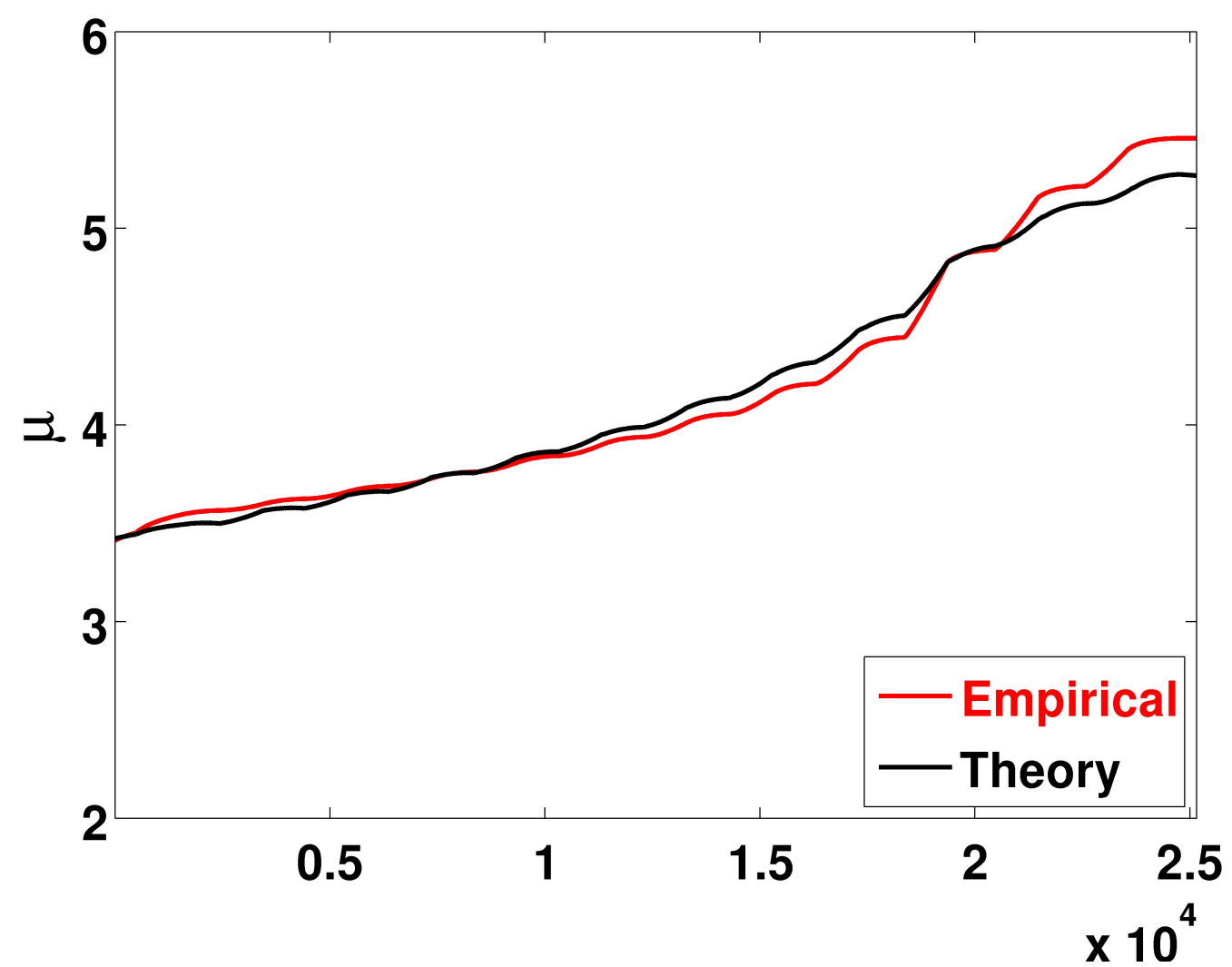

Figure 3. Calculated values of $\mu$, utilizing theoretical equation 18 and empirical equation 9 , all as a function of central film thickness $h_{c}(\mu \mathrm{m})$. 


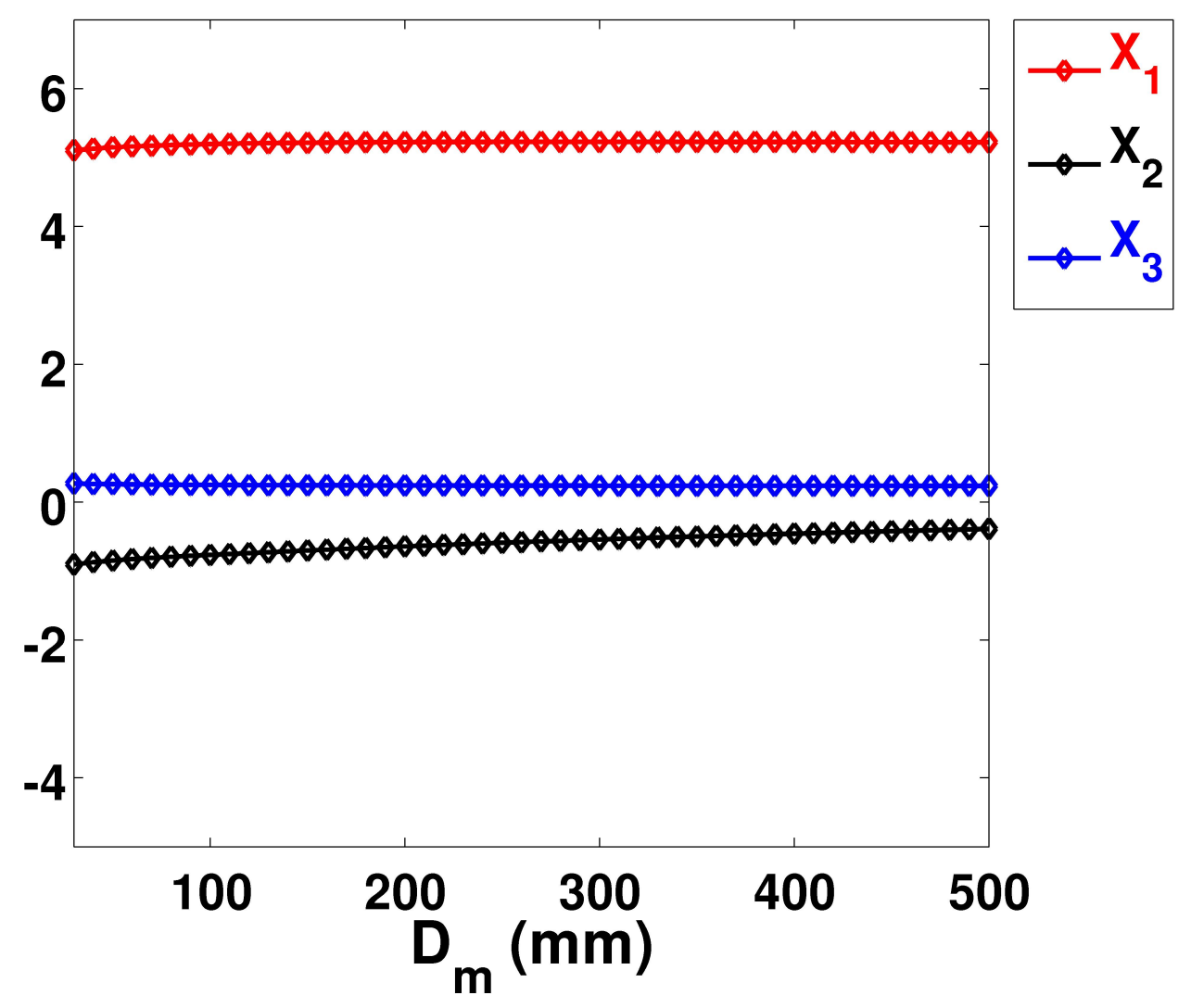

Figure 4. Coefficients of equation 18 as a function of average bearing diameter $d_{m}$.

so as to be proportional to the SKF NUP 2304-ECP cylindrical roller bearing. With a changing bearing diameter, the radius of the rollers $R(\mathrm{~m})$ was consistently adjusted so 25 roller bearings would consistently fit within the roller bearing circumference

$$
R=\frac{d_{m} \cdot \pi}{2 \cdot N_{r}},
$$

where $N_{r}=25$ represents the number of cylindrical roller bearings. As observed in Figure 4, the three coefficients, $X_{1}, X_{2}$, and $X_{3}$, change very little for changing average diameters $d_{m}(\mathrm{~m})$. The coefficient of determination $R^{2}$ was predicted for all values of $d_{m}(\mathrm{~m})$, and consistently the coefficient of determination $R^{2}$, as plotted in Figure 5, exceeded 0.99 .

\section{Conclusion}

In conclusion, a validated model to predict the probability of failures for roller bearings was developed. Empirical equations from SKF were developed from available data on commercial bearings to predict the $\mathrm{L}_{10}$ life based on known bearing conditions (lubricant viscosity, bearing speed, loads). These conditions were used, along with the roller bearing geometry, to predict the lubricant film thickness at the central point of contact. A thicker film thickness is expected to inherently have lower friction, and therefore a lower chance of lubricant failure, and a clear trend of lubricant thickness impacting the probability of bearing failure per revolution is observed. The relative load to the fatigue load is also taken into consideration; fatigue is considered a minor yet calculable influence on determining the bearing $\mathrm{L}_{10}$ life. This model demonstrates how the lubricant film thickness can be 


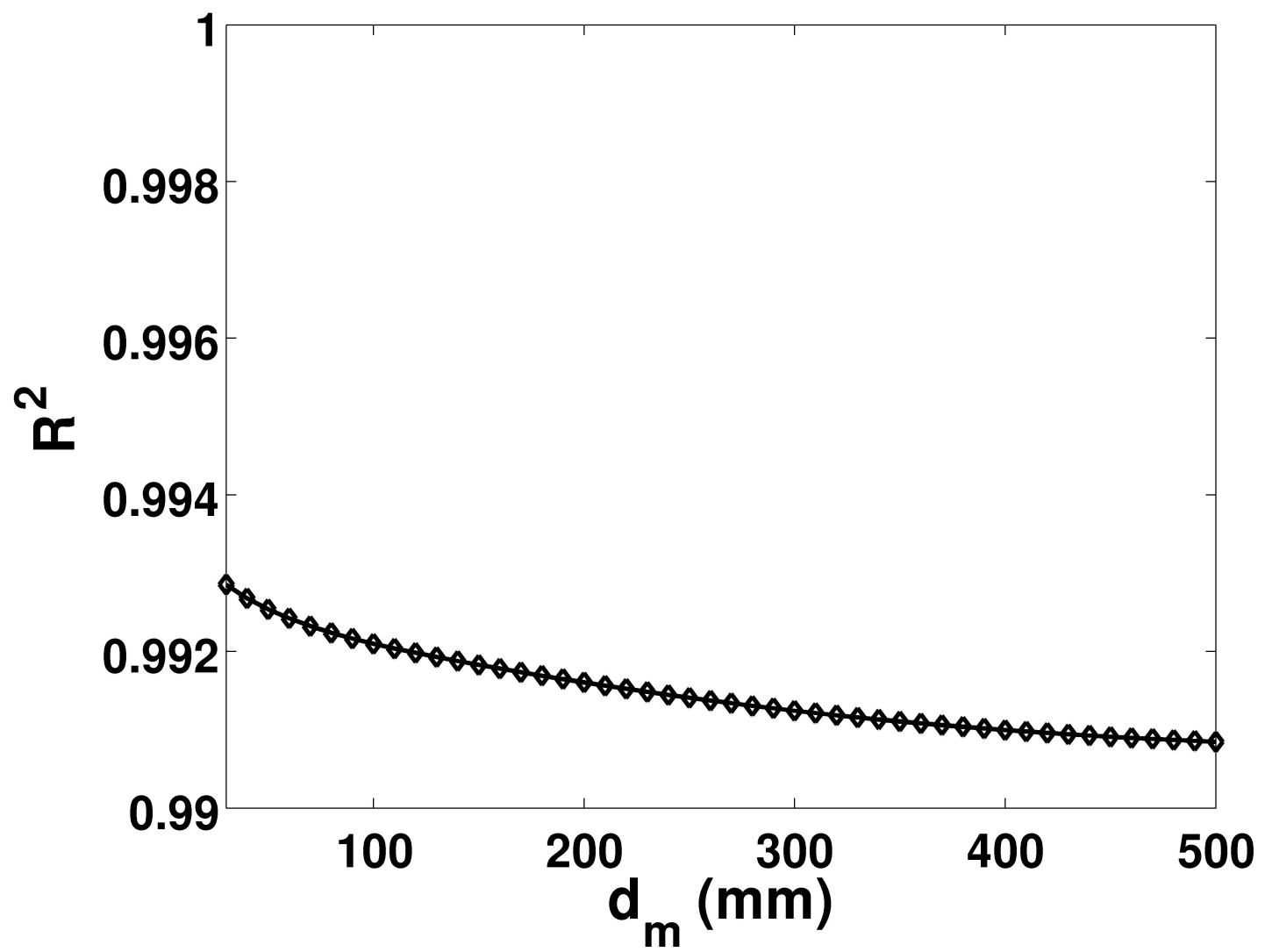

Figure 5 
used to obtain a reasonable approximation for the life and probability of failure in seizing of a roller bearing.

Acknowledgments: The author would like to acknowledge Lou Vocaturo, Clay Merkel, and Kevin Larkins for useful discussions.

Author Contributions: M.M. is the sole author of this manuscript.

Conflicts of Interest: The founding sponsors had no role in the design of the study; in the collection, analyses, or interpretation of data; in the writing of the manuscript, and in the decision to publish the results.

\author{
Abbreviations \\ The following abbreviations are used in this manuscript: \\ MDPI Multidisciplinary Digital Publishing Institute \\ DOAJ Directory of open access journals \\ BB Ball Bearing \\ $\mathrm{L}_{10} \quad$ Number of revolutions before $10 \%$ chance of failure \\ COF Coefficient of Friction
}

\title{
Bibliography
}

1. Stachowiak, G.; Batchelor, A. Engineering Tribology $4^{\text {th }}$ Edition; Butterworth-Heinemann: Oxford, UK, 2005.

2. Gohar, R. Elastohydrodynamics; World Scientific Publishing Company: Singapore, 2002.

3. Ranger, A.; Ettles, C.; Cameron, A. The Solution of the Point Contact Elasto-Hydrodynamic Problem. Proceedings of the Royal Society of London. Series A, Mathematical and Physical Sciences 1975, 346, 227-244.

4. Blau, P. On the nature of running-in. Tribology International 2005, 38, 1007-1012.

5. Hu, Y.; Li, N.; Tønder, K. A Dynamic System Model for Lubricated Sliding Wear and Running-in. Journal of Tribology 1991, 113, 499-505.

6. Suzuki, M.; Ludema, K. The Wear Process During the "Running-ln" of Steel in Lubricated Sliding. Journal of Tribology 1987, 109, 587-591.

7. Endo, K.; Kotani, S. Observations of Steel Surfaces Under Lubricated Wear. Wear 1973, 26, $239-251$.

8. Nam, J.; Ryou, H.; Cho, S. A numerical model of rotating bearings for thermo-mechanical coupled analysis. Proceedings of the 14th International Confernece on Simulation and Experiments in Heat Transfer and its Applications 2016, 106, 25-31.

9. Greenwood, J.; Williamson, J. Contact of Nominally Flat Surfaces. Proceedings of the Royal Society of London A 1966, 295, 300-319.

10. Bush, A.; Gibson, R.; Keogh, G. The Limit of Elastic Deformation in the Contact of Rough Surfaces. Mechanics Research Communication 1976, 3, 169-174.

11. Carbone, G. A slightly corrected Greenwood and Williamson model predicts asymptotic linearity between contact area and load. Journal of the Mechanics and Physics of Solids 2009, 57, 1093-1102.

12. McCool, J. Comparison of Models for the Contact of Rough Surfaces. Wear 1986, 107, 37-60.

13. Bush, A.; Gibson, R.; Thomas, T. The Elastic Contact of a Rough Surface. Wear 87-111, 35, 1975.

14. Persson, B. Contact mechanics for randomly rough surfaces. Surface Science Reports 2006, 61, $201-227$.

15. Finkin, E. Applicability of Greenwood-Williamson theory to film covered surfaces. Wear 1970, 15, $291-293$.

16. Cann, P.; Ioannides, E.; Jacobson, B.; Lubrecht, A. The lambda ratio - A critical Re-examination. Wear 1994, 175, 177-188.

17. Crook, A. The Lubrication of Rollers. Philosophical Transactions of the Royal Society of London, Series A, Mathematical and Physical Sciences, 250.

18. Archard, J. The Temperature of Rubbing Surfaces. Wear 1958, 2, 438-455.

19. Jaeger, J. Moving Sources of Heat and the Temperature at Sliding Contact. Proceedings of the Royal Society N.S.W. 1942, 76, 203-224.

20. Blok, H. Theoretical Study of Temperature rise at surfaces of actual contact under oiliness conditions. Proceedings of the Institute of Mechanical Engineering, General Discussion on Lubrication 1937, 2, 222-235.

21. Cameron, A.; Gohar, R. Theoretical and Experimental Studies of the Oil Film in Lubricated Point Contact. Proceedings of the Royal Society of London. Series A, Mathematical and Physical Sciences 1966, 291, 520-536. 
22. Hamrock, B.; Dowson, D. Isothermal Elastohydrodynamic Lubrication of Point Contacts, III Fully Flooded Results. NASA Technical Note 1976, D-8317.

23. Hamrock, B.; Dowson, D. Isothermal Elastohydrodynamic Lubrication of Point Contacts, I Theoretical Formulation. NASA Technical Note 1975, D-8049.

24. Hamrock, B.; Dowson, D. Isothermal Elastohydrodynamic Lubrication of Point Contacts, IV Starvation Results. NASA Technical Note 1976, D-8318.

25. Dowson, D. Elastohydrodynamic and micro-elastohydrodynamic lubrication. Wear 1995, 190, 125-138.

26. Lugt, P.M.; Velichov, S.; Tripp, J.H. On the Chaotic Behavior of Grease Lubrication in Rolling Bearings. Tribology Transactions 2009, 52, 581-590.

27. van Zoelen, M.; Venner, C.; Lugt, P. Prediction of film thickness decay in starved elasto-hydrodynamically lubricated contacts using a thin layer flow model. Journal of Engineering Tribology 2009, 223, 541-552.

28. Venner, C.H.; Popovici, G.; Lugt, P.M.; Organisciak, M. Film Thickness Modulations in Starved Elastohydrodynamically Lubricated Contacts Induced by Time Varying Lubricant Supply. ASME Journal of Tribology 2008, 130, 041501.

29. Venner, C.; van Zoelen, M.; Lugt, P. Thin layer flow and film decay modeling for grease lubricated rolling bearings. Tribology International 2012, 47, 175-187.

30. Johnson, K. Contact Mechanics; Cambridge University Press: 40 W 20th St, New York NY 10011, 1987.

Sample Availability: Samples of the compounds ...... are available from the authors. 